\title{
Removal of Reactive Red 74 Dye from Textile Industrial Waste using Zinc Oxide Nanoparticle
}

\author{
Zahra Monsef Khoshhesab $^{1}$, Katayon Gonbadi ${ }^{1}$, Gholamreza Rezaei Behbehani ${ }^{2}$ \\ ${ }^{1}$ Department of Chemistry, Payame Noor University, I.R of Iran \\ chemgonbadi@yahoo.com \\ monsefkh@yahoo.com
}

${ }^{2}$ Chemistry department, faculty of science, takestan branch, Islamic Azad university, takestan Iran

Grb402003@yahoo.com

\begin{abstract}
Global population growth and industrial activities in recent decades has been caused to enter excessive amount of pollutants to water resources. Industrial textile dyes are an important class of the pollutants in the sewage system. Disposal of the dyes in precious water resources must be avoided, however, and for that various treatment technologies are in use. Considering the toxicity of the pollutants, their removal from water resources is necessary. In this research, removal of reactive red 74, RR47, from aqueous solution by zinc oxide nanoparticles was investigated and the affecting parameters such as $\mathrm{pH}$, contact time and adsorbent mass on removal efficiency were determined. Langmuir and Freundlich isotherms were studied and the results indicated that the adsorption process obey the Langmuir and Freundlich isotherms. The experimental results also showed that the pseudo-second order kinetic equation could nicely describe the sorption kinetics.
\end{abstract}

Keywords: Removal; Dye; Zinc oxide nanoparticles; Reactive red 74

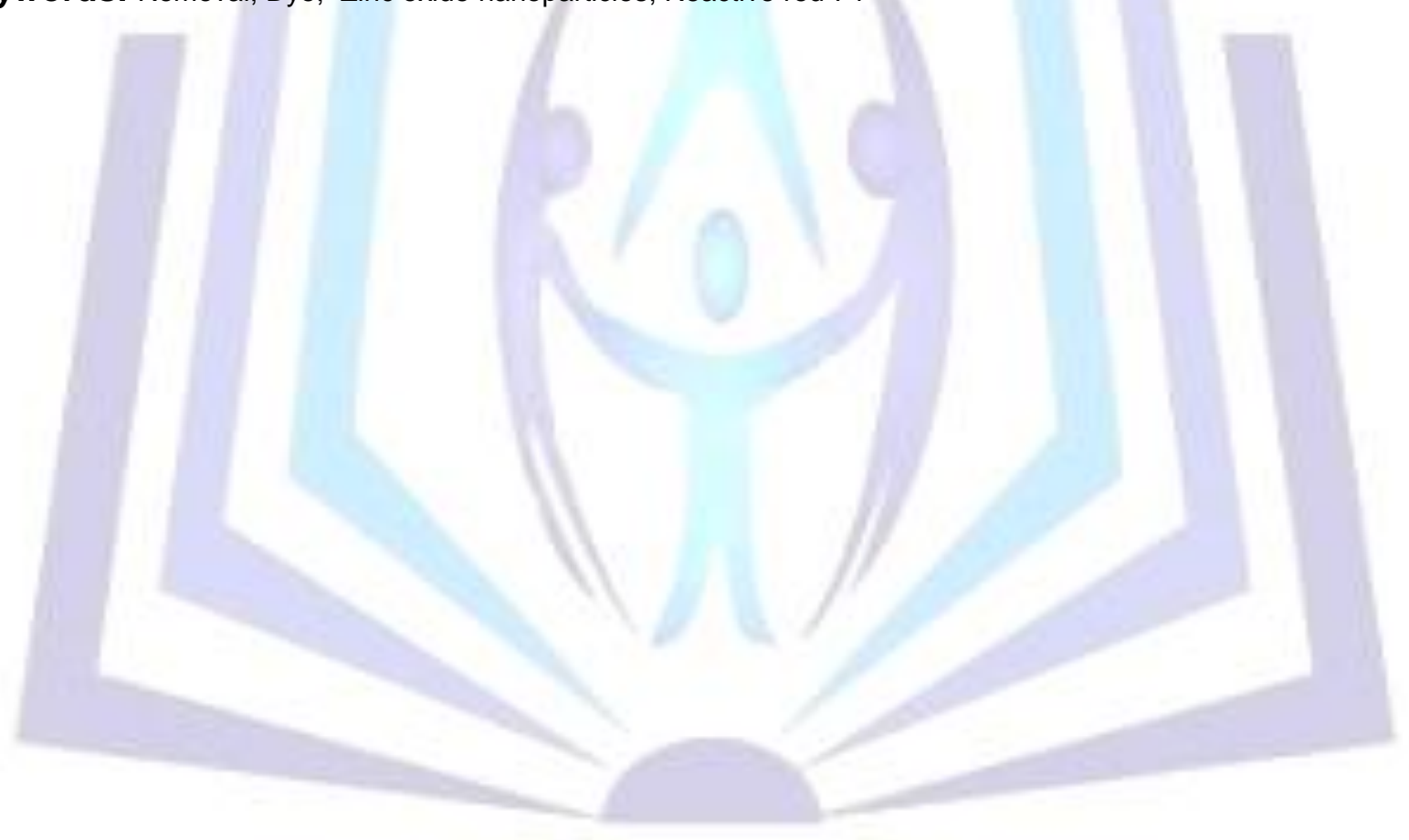

\section{Council for Innovative Research}

Peer Review Research Publishing System

Journal: Journal of Advances in Chemistry

Vol. 6, No. 3

editor@cirworld.com

www.cirworld.com, member.cirworld.com 


\section{Introduction}

Despite, the colors make our life beautiful, they carry the infection in the sewage system. The pollution caused by the discharge of textile dyes, has become a severe environmental problem since a long time ago. The effluent water from carpet manufacturing, dyeing, textile, pulp, and paper industries contain various types of dyes which should be removed before discharging the effluent to the environment to avoid health hazards and destruction of the ecosystem. The investigation of the removal of dyes from effluent wastewater of various industries has been going on for several years [1] The reactive dyes are colored compounds that have more than one reactive moiety per molecule or groups capable of forming covalent bonds between carbon atom of the dye ions or molecules and functional groups of the fabric (cellulose, wool, nylon and silk), making stable dye-fiber bond with poor washed-off properties [2, 3]. This is due to effective penetration and efficient dye fixation with cotton fabrics. The characteristics governed by the reactive groups are reactivity, dye-fiber bond stability, efficiency of the reaction with the fiber, and affinity [4]. Each of these group effects on the washing-off properties of the reactive dyes [5].

There are three major technologies available to remove dyes from water such oxidation, adsorption and flocculationprecipitation. These methods are only effective for low concentrations of organic matter present in water. In other words, significant dilution of the water containing dye is necessary for the effective use of the oxidation method. The separation of dyes based on adsorption on peat, wood, silica, bagasse pith, activated carbon and slag, and bagasse fly ash have been proposed. These adsorption methods are capable of removing the dyes from concentrated wastewater [6]. However, regeneration of most of the adsorbents is difficult except for activated carbon. The adsorption treatment using activated

Carbon as adsorbent is quite expensive. Therefore, researchers have been looking to replace cheaper costly wastewater treatment. Many natural materials (organic and inorganic), plants industrial wastes, agricultural wastes and biological adsorbents have been studied for this purpose [7]. Titanium dioxide is one of the most Photo-catalyst used to remove organic materials. Zinc oxide is another Semiconductor that has been used in recent years as Photo-catalyst. Also, the use of hybrid adsorbents for dye removal from water have been reported [8]. Studies show that the removal of reactive dyes having Azo group used for coloring cellulose, zinc oxide has greater efficiency than titanium dioxide [9]. The use of mentioned semiconductor Photo-catalyst largely is due to easy availability, low cost, non-toxic and hazardous organic substances decomposition into minerals such as mineral acids, carbon dioxide and water [9]. In this study, the removal of reactive dye Red 74 from aqueous solutions using Nano-sized zinc oxide was studied. This dye is orchid bouquet and is a Azo dye with a $\mathrm{N}=\mathrm{N}$ group which is soluble in water and in the textile industry for printing on cellulosic fabrics is used. The main objective of this study was to investigate the possibility of removing dye contaminants from industrial wastewater and textile industry effluents using zinc oxide nanoparticles. Therefore, the effect of different factors such as solution $p \mathrm{H}$, the contact time of adsorbent with a solution containing the dye on the adsorption efficiency of RR74 has been investigated and optimum conditions for dye removal by zinc oxide nanoparticles were determined. The adsorption kinetics have been studied in detail, and the adsorption isotherms were also studied.

\section{Materials}

Reactive dye red 74 with brand AMARYL Brilliant pink B was purchased from the Hindi Cosmonaut Chemicals Company. Zinc oxide Nano-particles with an average particle size of $10 \mathrm{NM}$ and a flower-shaped morphology was synthesized by the chemical precipitation method and was used as adsorbent. Sodium hydroxide and nitric acid were purchased from Merck.

\section{Instruments and appliances used}

The structure and morphology of zinc oxide NANO-particles by X-ray diffraction machine (Phillips, Model XLS30) and scanning electron microscope (Philips model PW1800) were studied. To measure the dye concentration by two beams Shimadzu ML1600 spectrophotometer made in Japan, was conducted. $\mathrm{pH}$ of the solutions using a $\mathrm{pH}$ meter (Metroum, Model 827) was measured. For stirring the solutions, a magnetic stirrer with a speed of $150 \mathrm{rpm}$ and for weighing samples SARTERIUS balance with the precision of $\pm 0.0001 \mathrm{~g}$ was used.

\section{Methods}

Zinc oxide nanoparticles were synthesized from microscale zinc oxide using a simple precipitation method. First, $48 \mathrm{~g}$ of ammonium bicarbonate is dissolved in $60 \mathrm{ml}$ of distilled water and then $24 \mathrm{~g}$ of microscale zinc oxide is added to the above solution in two stages. For this purpose, initially $8 \mathrm{~g}$ zinc oxide into ammonium bicarbonate solution, while stirring in water bath of $60^{\circ} \mathrm{C}$, was added. After half an hour, the rest of zinc oxide (16 g) was added to the suspension and for 1.5 hours was stirred at the same temperature. In the end, the resulting slurry was then dried at $70^{\circ} \mathrm{C}$ and for $2 \mathrm{~h}$ was calcined in a furnace of $400^{\circ} \mathrm{C}$. Given the range of XRD (Figure 1) and based on the Scherer equation, the average particle size of $10 \mathrm{~nm}$ was obtained. The SEM image of the prepared sample (Figure 2) shows the structure of the flowershaped of Zinc oxide nanoparticles. 


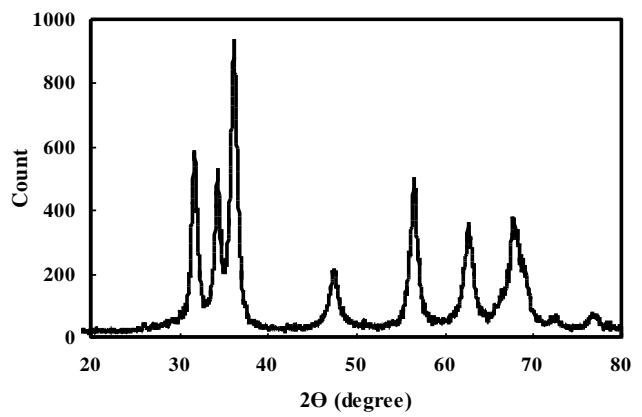

Figure 1 XRD spectra of zinc oxide nanoparticles

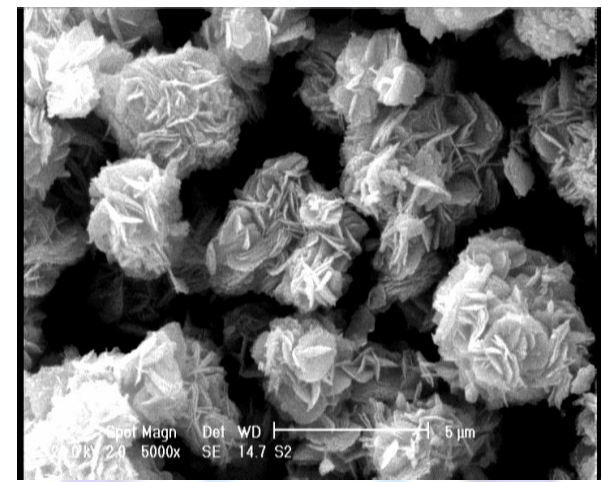

Figure 2 SEM image of zinc oxide nanoparticles

\section{Removal of reactive dye Red 74}

In order to investigate the potential of Zinc oxide nanoparticles to remove RR74, a certain mass of the adsorbent added into $50 \mathrm{ml}$ solution containing dye with a certain concentration and the resulting suspension was stirred by a magnetic stirrer $(150 \mathrm{rpm})$ at $25^{\circ} \mathrm{C}$. After an appropriate time, the mixture was filtered through a filter paper and by measuring the solution absorbance at $547 \mathrm{~nm}$ wavelength, the residual dye concentration in solution was determined. The optimized conditions were approached in the maximum capacity of absorption. The impact of various factors on the removal efficiency of the dye was investigated. The optimized conditions were determined by changing one factor at a time. Therefore, the effect of $\mathrm{pH}$ changes ranging from 3 to 10 , the mass of the adsorbent $(0.01-0.3 / 0 \mathrm{~g})$, initial concentration of RR74 (5-100 mg/l) and stirring time (30-180 min) were studied. In all experiments, the concentration of RR74 before and after exposure to the adsorbent was calculated using a calibration curve. The removal efficiency and capacity of absorption were calculated using equations 1 and 2 as follows:

$$
\begin{gathered}
R=\frac{100\left(C_{0}-C_{e}\right)}{C_{0}} \\
q_{e}=\frac{\left(C_{0}-C_{e}\right) V}{m}
\end{gathered}
$$

Where $R$ is the percentage of the dye removal, $q_{\mathrm{e}}$ is the amount of the adsorbed RR74 at equilibrium per unit mass of adsorbent $(\mathrm{mg} / \mathrm{g}), C_{0}$ is the initial concentration of RR74 $(\mathrm{mg} / \mathrm{g}), C_{\mathrm{e}}$ is the residual dye concentration in solution $(\mathrm{mg} / \mathrm{g}), \mathrm{V}$ is the volume of solution (L) and $m$ is the mass of Zic oxide nanoparticles $(g)$. An example of the UV-visible spectrum solution containing RR74 before and after exposure to the adsorbent was shown in Figure 3. Reduce the absorption of RR74 indicating the dye absorption by the adsorbent and thus indicate the ability of zinc oxide nanoparticles for the removal of RR74. 


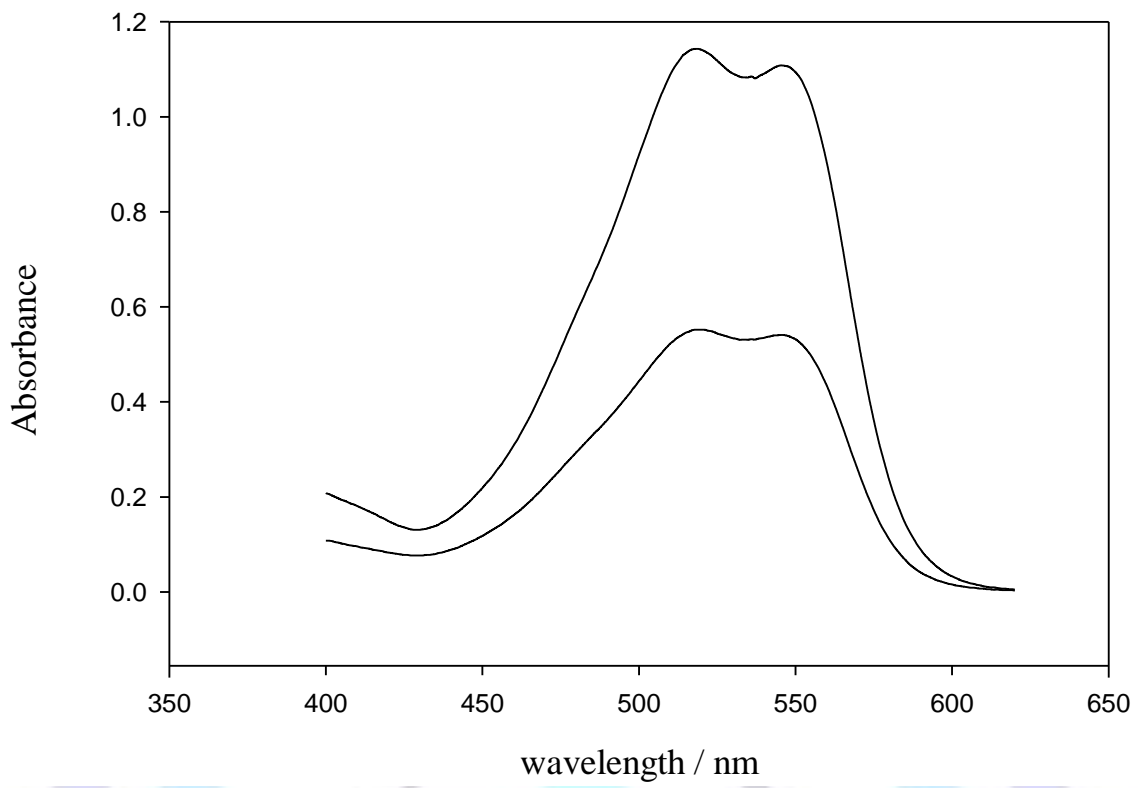

Figure 3 Absorption spectra of dye Reactive Red 74 (75 milligrams per liter) Before (down) and after contact with Results and Discussion

\section{Effect of solution $\mathrm{pH}$ on the dye removal}

$\mathrm{pH}$ of the aqueous solution is a very important factor in the adsorption process. The dye binding to the adsorbent surface is carried out by surface groups that are highly $\mathrm{pH}$ dependent. The effect of $\mathrm{pH}$ on the dye absorption by the oxide zinc nanoparticles have been shown in the figure 4. As it is clear in figure 4, the removal efficiency of zinc oxide nanoparticles decreases gradually with increasing $p \mathrm{H}$, and most dye removal occurs at $p \mathrm{H} 3$, thereby $p \mathrm{H}=3$ was used as the optimized one for further testing. This behavior could be explained due to the acid $\mathrm{pH}$ of zero point charge $(\mathrm{pH} \sim 8)$ and electrostatic interactions between charged particles of zinc oxide nanoparticles and the dye molecules. Considering that the surface of Zinc oxide nanoparticles at $p \mathrm{H}<3$ has the positive charge and at $p \mathrm{H}>8$ has a negative charge, therefore a significant decrease in the absorption capacity at $\mathrm{pH}>8$ is due to the repulsive forces between the negatively charged dye molecule and the number of positive charges on the adsorbent surface.

The adsorption capacity solution is much higher in acidic solutions than those in neutral and alkaline conditions. This may be due to the number of positive charges on the adsorbent surface which leads to the no rejection of the negatively charged dye molecule, and thereby increasing the adsorption.

\section{The effect of contact time on the dye removal}

To investigate the effect of contact time of the dye on the absorption value, absorbing dye by zinc oxide nanoparticles in optimum conditions was investigated and the results were presented in figure 5 . As it was shown in figure 5, the absorption rate was initially high and gradually decreases, and after $60 \mathrm{~min}$, the removal efficiency roughly remains constant. This behavior indicates that the kinetics of dye absorption on the adsorbent surface is relatively faster, so that more than $60 \%$ absorption occurs in the first 5 minutes. The high rate of the dye absorption at first, and gradually reduce the absorption rate is due to the certain number of adsorption sites on the adsorbent surface and with the gradual absorption of dye molecules on the adsorbent surface, the free sites on the adsorbent surface is decreased, therefore, the free dye species in the solution compete for adsorption on the remaining sites. Based on the results of this study, the dye absorption approaches to the equilibrium in 60 minutes, and therefore, the optimized time is 60 minutes. 


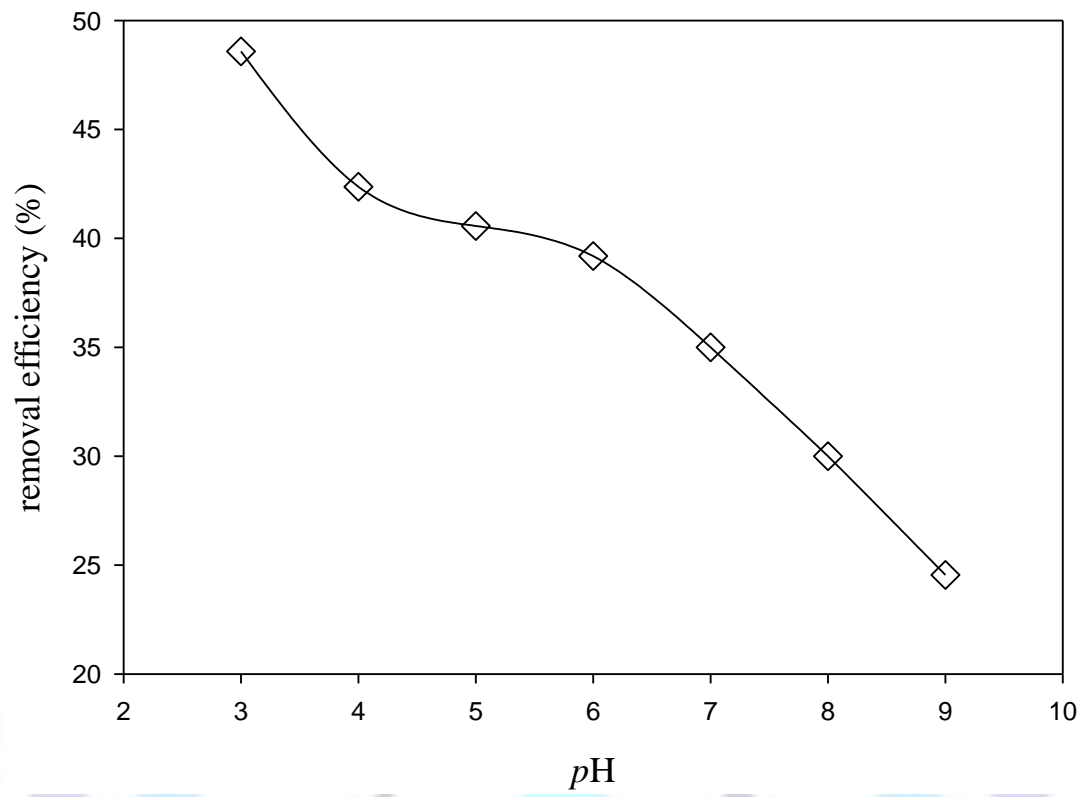

Figure 4 Effect of $p H$ on the dye removal efficiency, R\%, by zinc oxide nanoparticles (Initial dye concentration: 75 milligrams per liter, solution volume: $50 \mathrm{ml}$, the amount of adsorbent: $0.05 \mathrm{~g}$, contact time: $60 \mathrm{~min}$ )

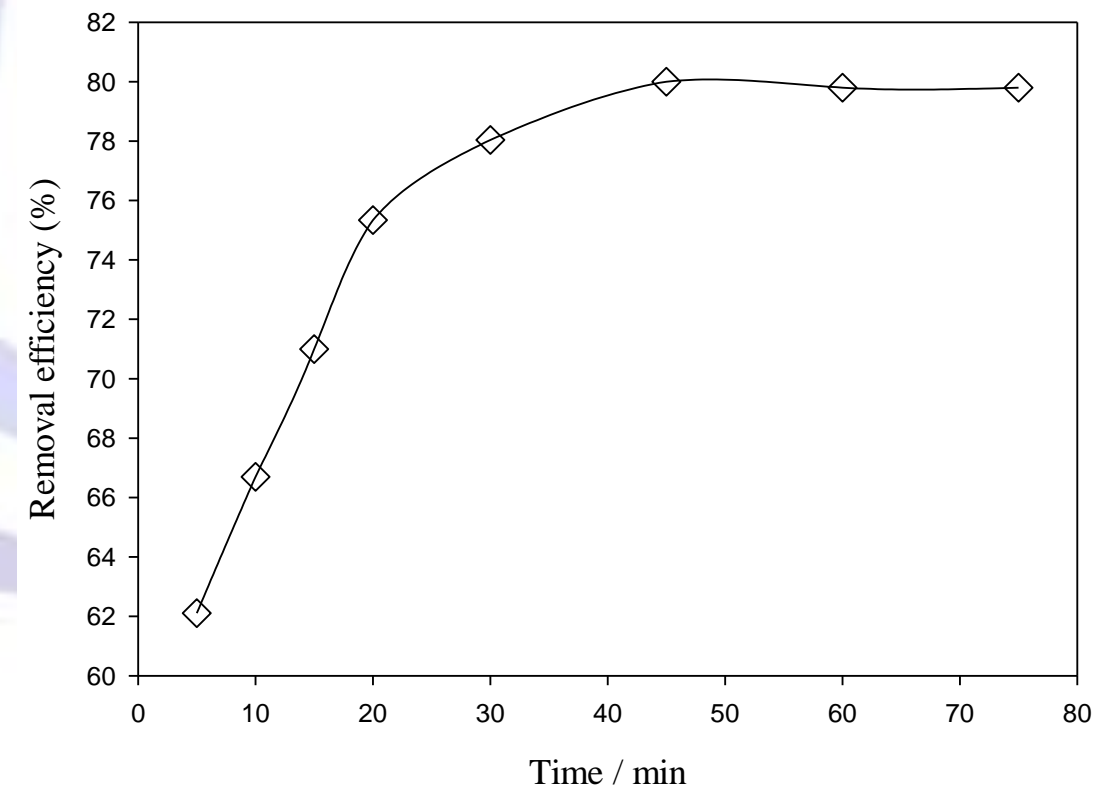

Figure 5 Effect of contact time on the dye removal efficiency, R\%, by zinc oxide nanoparticles (Initial dye concentration: $75 \mathrm{mg} \mathrm{L}^{-1}$, solution volume: $25 \mathrm{~mL}$, the amount of adsorbent: $0.05 \mathrm{~g}, \mathrm{pH}: 3$ ) 


\section{Optimization of amount of adsorbent}

The effect of the amount of adsorbents for the removal of the dye was investigated at the optimal $\mathrm{pH}$ of 3 . For all the experiments, initial concentration of the dye solution was kept constant at $75 \mathrm{mg} / \mathrm{L}$, initial volume was $25 \mathrm{~mL}$ and contact time was $60 \mathrm{~min}$. The results were depicted in figure 6 shows that absorption rate was decreased sharply with decreasing the amount of zinc oxide nanoparticles up to $0.2 \mathrm{~g}$. Then the absorption rate was not changed significantly with decreasing amount of adsorbent. Therefore, $0.2 \mathrm{~g}$ of the adsorbent was used as the optimum value in subsequent experiments.

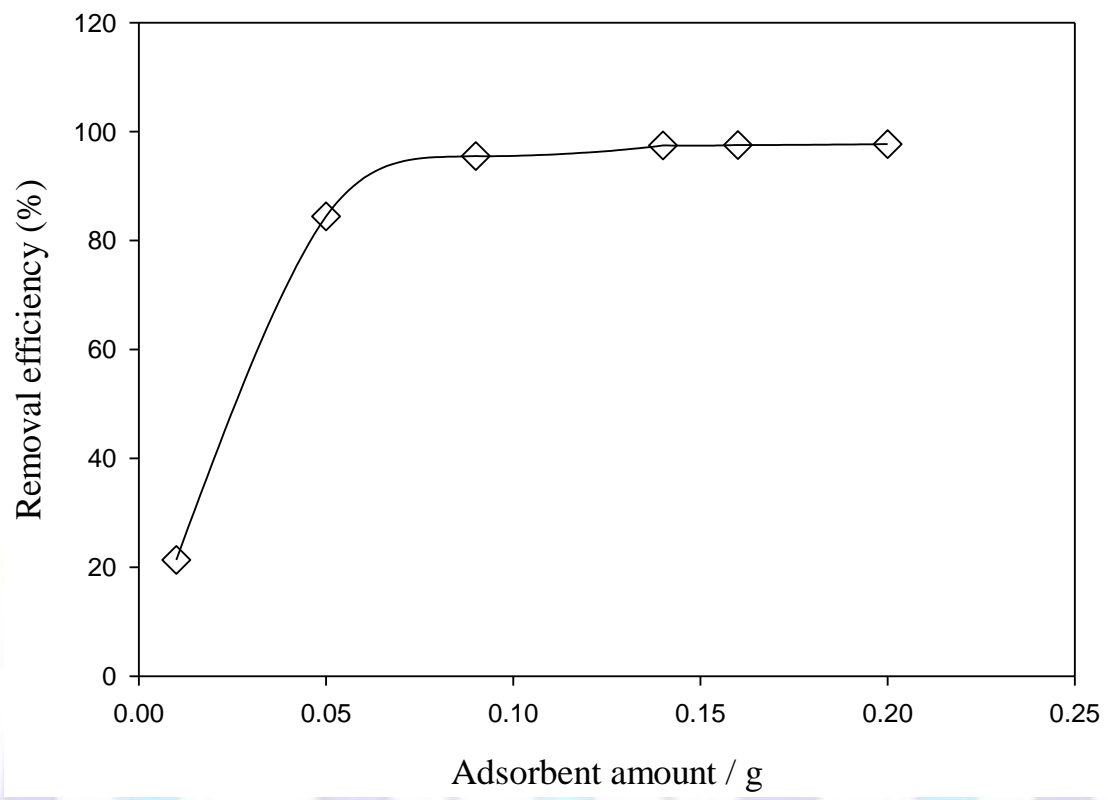

Figure 6 The effect of adsorbed amount on the dye removal (Initial dye concentration: $75 \mathrm{mg} / \mathrm{L}$; solution volume: $25 \mathrm{~mL}$; contact time: $60 \mathrm{~min}$ and $\mathrm{pH}=3$ )

\section{Dye removal from textile wastewater}

After determining the optimal conditions for the absorption of dye from aqueous solutions, zinc oxide nanoparticles capability for the removal of reactive red dye 74 from wastewater of a textile factory, was tested. Two samples (50 $\mathrm{mL})$ of effluent, with $0.2 \mathrm{~g}$ adsorbent were contacted in the optimum conditions. $100 \mathrm{mg}$ of the dye was manually added to a sample, and another sample without adding any dye was studied. The results indicated that about $90 \%$ of the dye were removed. Besides RR74, industrial textile contains large amounts of other common dyes, therefore, the results of this study indicate the high performance of Zinc oxide nanoparticles for RR74 removal from wastewater.

\section{The kinetic study of the adsorption process}

The kinetic study provides the required information about the absorption mechanism. Also, the rate of absorption of solutes by the adsorbent at the interface of solid-liquid aided these studies is described. A simple kinetic analysis of adsorption is the pseudo-first-order equation;

$$
\log \left(q_{e 1}-q_{t}\right)=\log q_{e 1}-\frac{k_{1}}{2.303} t
$$

Where $q_{\mathrm{e} 1}$ and $q_{1}$ are the amount of the dye adsorbed at equilibrium and at times, in $\mathrm{mg} / \mathrm{g}$ respectively, and $K_{1}$ is the first order rate constant, was applied to the present studies of RR74 dye adsorption. The values of $\log \left(q_{e 1}-q_{t}\right)$ against $t$ were plotted (figure 7) and the obtained kinetic data of RR74 dye removal were listed in table 1. Adsorption kinetics for some system can also be described by a pseudo-second order reaction.

$$
\frac{t}{q_{t}}=\frac{1}{k_{2} q_{e 2}^{2}}+\frac{1}{q_{e 2}} t
$$

The equilibrium adsorption capacity $\left(q_{e}\right)$, and the second-order rate constant $k_{2}(\mathrm{~g} / \mathrm{mg} \mathrm{min})$ can be determined experimentally from the slope and intercept of plot $t / q_{t}$ versus t. The applicability of the pseudo-second order models can be examined by linear plot $t / q_{t}$ vs $t$ respectively as shown in (Figure 6 ). The correlation coefficient, $r^{2}$, shows that the 
pseudo-second order model an indication of a chemisorptions mechanism, fits the experimental data slightly better than the pseudo-first order model. Therefore the adsorption of RR74 can be approximated more favorably by the pseudosecond order model. The $k_{2}\left(\mathrm{mg} \mathrm{g}^{-1} \mathrm{~min}^{-1}\right)$ and $q_{e}\left(\mathrm{mg} \mathrm{g}^{-1} \mathrm{~min}^{-1}\right)$ values are listed in table 1.

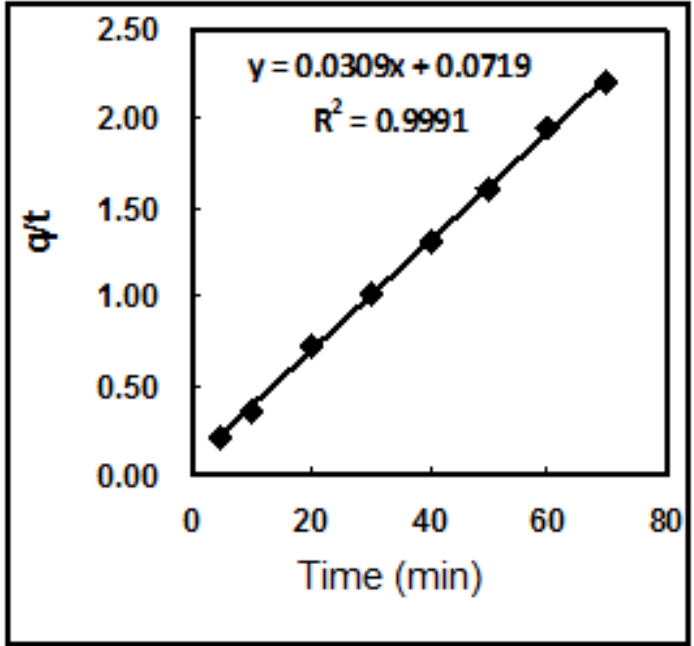

b

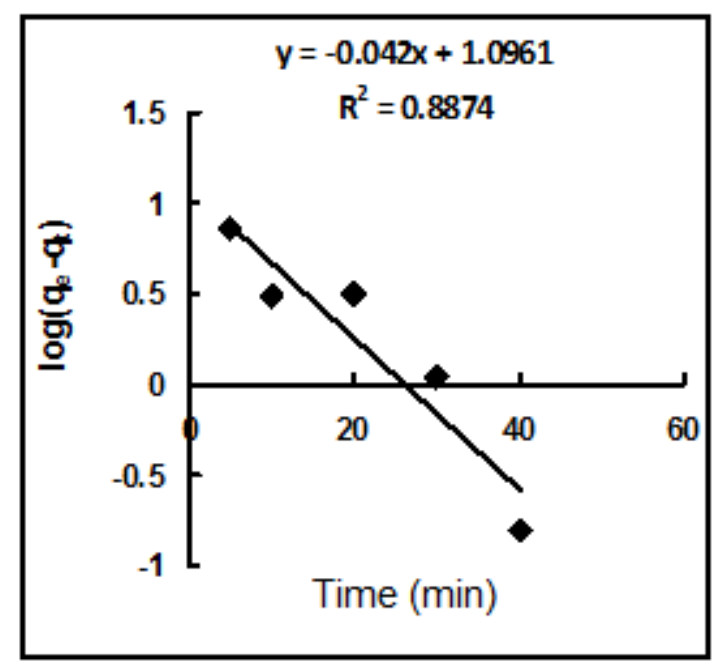

a

Figure 7 Kinetic diagram pseudo-first-order kinetic model (a) and pseudo-second-order (b)

Table 1. Values Kinetics

\begin{tabular}{ccccccccc}
\hline & \multicolumn{3}{c}{ pseudo-first-order Model } & & \multicolumn{3}{c}{ pseudo-second-order } \\
\cline { 2 - 8 } & $\mathrm{q}_{\mathrm{e} 1}$ & $\mathrm{k}_{1}$ & $\mathrm{R}^{2}$ & $\mathrm{q}_{\mathrm{e} 2}$ & $\mathrm{k}_{2}$ & $\mathrm{q}_{\mathrm{e}(\mathrm{exp})}$ & $\mathrm{R}^{2}$ \\
& $(\mathrm{mg} / \mathrm{g})$ & $(\mathrm{g} / \mathrm{mg} \cdot \mathrm{min})$ & & $(\mathrm{mg} / \mathrm{g})$ & $(\mathrm{g} / \mathrm{mg} \cdot \mathrm{min})$ & $(\mathrm{mg} / \mathrm{g})$ & \\
\hline $\begin{array}{c}\text { Red } \\
\text { Reactive }\end{array}$ & 12.47 & 8.82 & 0.887 & 32.36 & 0.42 & 30.77 & 0.999 \\
\hline
\end{tabular}

\section{Study of adsorption isotherms}

Most important models describing adsorption are Langmuir and Freundlich models are as follows [9-11]:

$$
\begin{gathered}
\log q_{e}=\frac{1}{n} \log C_{e}+\log K_{f} \\
\frac{C_{e}}{q_{e}}=\frac{1}{b q_{m}}+\frac{C_{e}}{q_{m}}
\end{gathered}
$$

$q_{\mathrm{e}}$ is the amount of dye adsorbed per unit mass of adsorbent at equilibrium $(\mathrm{mg} / \mathrm{g}), \mathrm{C}_{\mathrm{e}}$ the equilibrium concentration of dye $(\mathrm{mg} / \mathrm{g}), K_{\mathrm{f}}$ and $n$ are the intensity and capacity of absorption, respectively. $q_{\mathrm{m}}$ is the adsorption capacity $(\mathrm{mg} \mathrm{g} / \mathrm{g})$ and $\mathrm{b}$ is the Langmuir constant represents the intensity of absorption. In order to investigate the adsorption isotherms, $0.2 \mathrm{~g}$ zinc oxide nanoparticles to $50 \mathrm{mg}$ of dye solution with a concentration of $5-200 \mathrm{mg} / \mathrm{L}$ at $\mathrm{pH} 3$ is added and after stirring for 60 minutes, then the obtained data in equilibrium conditions using Freunlich and Langmuir absorption models were listed in table 1 and shown in figure 8 . Langmuir isotherm parameters listed in table 1 , show that the correlation coefficients $\left(r^{2}=\right.$ $0.997)$ fitting of the data by Langmuir isotherm is more consistent. Also using the values of $R_{L}\left(1>R_{L}>0\right)$ indicate that the absorption obeys the Langmuir isotherm. The results of Freundlich isotherm show that the correlation coefficient is 0.935 and $n=2.1$. Zinc oxide nanoparticles absorption of reactive red 74 follow the two isotherms and the dye molecules occupy the sites on the zinc oxide nanoparticle surface chemically. 

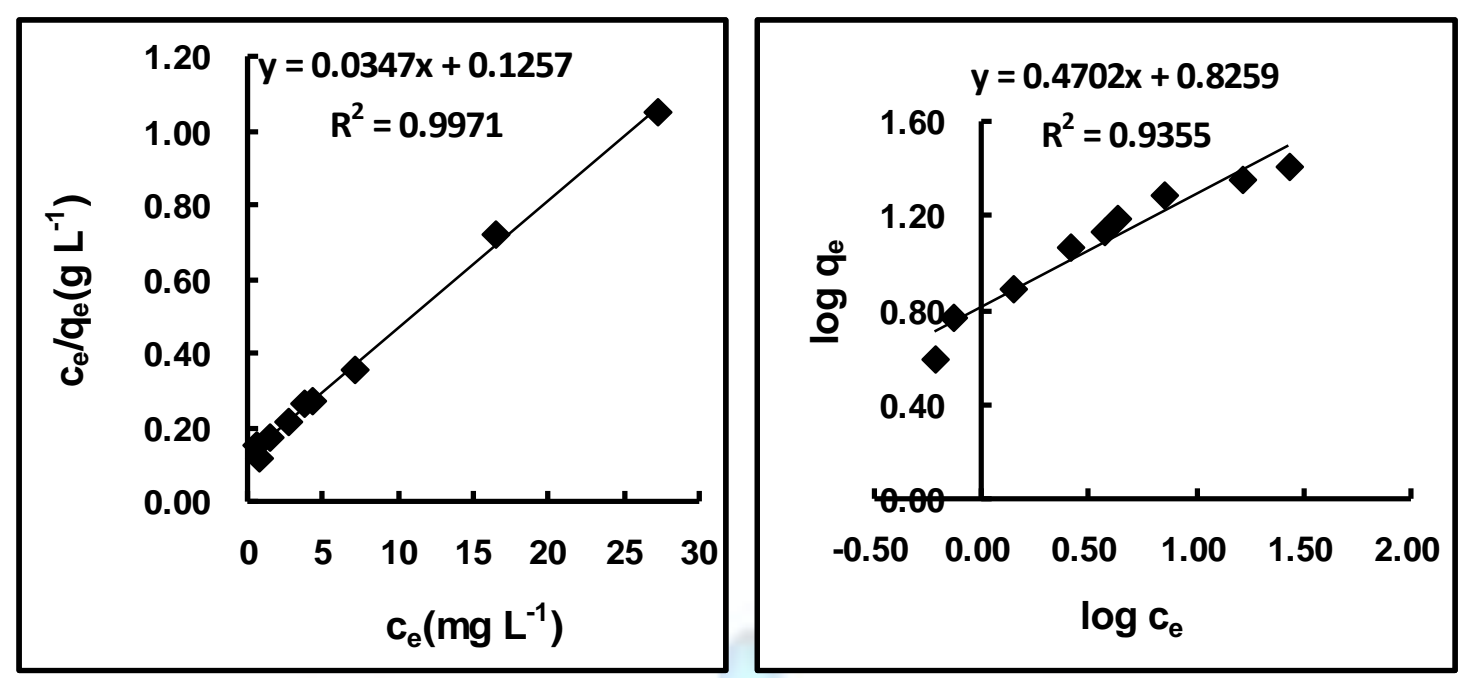

Figure 8- Diagrams of Langmuir isotherms (a) and FREUNDLICH (b)

\section{Conclusion}

In this study, the absorption efficiency of zinc oxide nanoparticles in the removal of reactive Red 74 dye from aqueous solutions was investigated. The results showed that the dye removal efficiency is significantly dependent on $\mathrm{pH}$, and the maximum percentage of dye removal at $\mathrm{pH} 3$ and 60 minutes was approached. The optimum amount of required adsorbent for the removal of the dye is $0.2 \mathrm{~g}$. The absorption of pollutants nicely followed the Langmuir and Freunlich isotherm and the maximum adsorption capacity of $28.8 \mathrm{mg} / \mathrm{g}$ was obtained. The kinetics of the dye absorption by zinc oxide nanoparticles obyes quasi-second-order model. The results showed that zinc oxide nanoparticles as biocompatible adsorbents remove the reactive red 74 dye successfully from aqueous solutions especially industrial textile.

\section{References}

[1] Modirshahla, N., Behnajady, M.A. and Ghanbary, F. 2007. Decolorization and mineralization of C.I. Acid Yellow 23 by Fenton and photo-Fenton processes. Dyes and Pigments 73, 305-310.

[2] Crini, G. 2006. Non-conventional low-cost adsorbents for dye removal: A review. Bioresource. Technol. 97, 10611085.

[3] Robinson, T., McMullan, G., Marchant, R. and Nigam, P. 2001. Remediation of dyes in textile effluent: a critical review on current treatment technologies with a proposed alternative. Bioresour. Technol. 77, 247-255.

[4] Amat, A.M., Arques, A., Lopez, F. and Miranda M.A. 2005. Solar photocatalysis to remove paper mill wastewater pollutants. Sol. Ener. 79, 393-401.

[5] Balcioglu, I.A. and Arslan, I. 1998. Application of photocatalytic oxidation treatment to pretreated and raw wastewaters from the kraft bleaching process and textile industry. Environ. Pollu. 103, 261-268.

[6] Balcioglu, I.A. and Cecen, F. 1999. Treatability of kraft pulp bleaching wastewater by biochemical and photocatalytic oxidation. Wat. Sci. Techno. 40 (1), 281-288.

[7] Boyd, L.K. and Almquist, C.B. 2004. The application of photocatalysis on $\mathrm{TiO}_{2}$ for degrading COD in paper mill wastewaters. TAPPI J. 3 (9), 9-15.

[8] Catalkaya, E.C. and Kargi, F. 2008. Advanced oxidation treatment of pulp mill wastewater for TOC and toxicity removal. J. Environ. Manage. 87, 396-404.

[9] Gaya, U.I. and Abdullah, A.H. 2008. Heterogeneous photocatalytic degradation of organic contaminants over titanium dioxide: A review of fundamentals, progress and problems. J. Photochem. Photobio. C: Photochem. Rev. 9, 1-12.

[10] Gogate, P.R. and Pandit, A.B. 2004. A review of imperative technologies for wastewater treatment I: oxidation technologies at ambient conditions. Adv. Environ. Rese. 8, 501-551.

[11] Rezaei Behbehani, G., A. A. Saboury A.A. and Taleshi, E. 2008. A comparative study on direct calorimetric determination of denaturation enthalpy for lysozyme in sodium dodecyl sulfate and dodecyltrimethylammonium bromide. Journal of Solution Chemistry 37, 619-629. 